\title{
Selective sperm binding to pig oviductal epithelium in vitro
}

\author{
A. M. Petrunkina ${ }^{1}$, R. Gehlhaar ${ }^{1}$, W. Drommer ${ }^{2}$, D. Waberski ${ }^{1 *}$ \\ and E. Töpfer-Petersen ${ }^{1}$ \\ ${ }^{1}$ Institute for Reproductive Medicine and ${ }^{2}$ Institute for Pathology, School of Veterinary \\ Medicine Hannover, Bünteweg 15, D-30559 Hannover, Germany
}

\begin{abstract}
The sperm reservoir in the caudal isthmus of the oviduct of a number of species is created by binding of spermatozoa to oviductal epithelium. The sperm reservoir fulfills a number of functions such as control of sperm transport, maintenance of sperm viability and modulation of capacitation. The initial capacities of ejaculated and epididymal boar spermatozoa to bind to oviductal epithelium were investigated using a modified pig oviductal explant assay. The number of spermatozoa that bound to $0.01 \mathrm{~mm}^{2}$ of explant surface was used as the parameter of binding capacity. Binding of spermatozoa to oviductal epithelial explants was dependent in a linear manner on the number of spermatozoa added $(P \leqslant 0.05)$. No difference was found in initial sperm binding between isthmic and ampullar
\end{abstract}

explants. There was no effect of the stage of the oestrous cycle or the reproductive status of the female donor. There was a significant effect $(P \leqslant 0.05)$ of the individual boar on the binding index. The binding index correlated negatively with the percentage of spermatozoa with cytoplasmic droplets and the percentage of morphologically abnormal spermatozoa $(P \leqslant 0.05)$. Epididymal spermatozoa showed significantly lower initial binding capability than did ejaculated spermatozoa from the same boars $(P \leqslant 0.05)$; therefore, components of seminal plasma may play a role in the binding process. The individual differences revealed by this study and their relation to morphology and contact of spermatozoa with seminal fluid indicate a selective function of sperm-oviduct binding.

\section{Introduction}

Many millions of spermatozoa are deposited in the female genital tract at ejaculation. Only a few thousand of these spermatozoa enter the oviduct, a few reach the ampulla at the time of ovulation and one spermatozoon fertilizes the egg. In a number of species, for example pigs (Hunter, 1981; Suarez et al., 1991), mice (Suarez, 1987), hamsters (Smith and Yanagimachi, 1991), rabbits (Overstreet and Cooper, 1978a,b), horses (Dobrinski et al., 1996a,b) and cows (Hunter et al., 1991; Lefebvre et al., 1995a; Suarez et al., 1997), it has been shown that after passing through the uterus, spermatozoa are held back in the caudal region of the isthmus due to binding of the spermatozoa to the epithelium lining the duct. The oviductal sperm reservoir formed in this way may fulfill a number of functions: firstly, it may control sperm transport to the ampulla, thereby contributing to the prevention of polyspermic fertilization; secondly, sperm viability is maintained during sperm binding to the oviductal epithelium to span the time between oestrus and fertilization; and thirdly, capacitation is modulated by the oviductal microenvironment to synchronize sperm fertilizing ability with the time of ovulation (for reviews see Smith (1998) and Suarez (1998, 1999)). The need to maintain viability and regulate sperm

*Correspondence

Email: Dagmar.Waberski@tiho-hannover.de capacitation may be mutually associated events as capacitational changes reduce the lifespan of spermatozoa. Capacitation, which is defined as the sequence of cellular and membrane alterations enabling a spermatozoon to undergo the acrosome reaction in response to the zona pellucida of the ovulated egg, is a periovulatory event. Although capacitation can be achieved in vitro simply by incubating spermatozoa in artificial fertilization media, there is increasing evidence indicating that, in vivo, at least the final stages are programmed by ovarian factors affecting sperm function directly or by the transfer of the corresponding signals by the endosalpinx (Hunter, 1997; Hunter et al., 1998). In pigs, the caudal region of the oviductal isthmus appears to be specialized for these purposes. The caudal region of the isthmus is particularly efficient in neutralizing seminal components and in exerting effects on the sperm cell that are responsible for modulation and initiation of sperm capacitation (Hunter et al., 1998). Although the underlying mechanisms are essentially unknown, a gradient in local endocrine modulation by the adjacent ovary offers one explanation for the functional specialization of the isthmus (Hunter et al., 1998; Suarez, 1999, 2001). Although in vitro systems lack both the local regulatory function of the ovaries on oviductal epithelium and the physical barriers of oviductal mucus (Hunter et al., 1998), they allow cellular and molecular studies of basic principles of sperm-oviduct interaction. A fast, accurate and sensitive assay enabling characterization of spermoviduct binding is required to perform molecular studies on 
sperm-oviduct interactions. Oviductal explant assays in hamsters, cows and horses showed that sperm binding occured to a greater extent in uncapacitated compared with capacitated spermatozoa, and sperm-oviduct binding was identified as a carbohydrate-mediated event (DeMott et al., 1995; Lefebvre and Suarez, 1996; Lefebvre et al., 1995b, 1997). Although oviductal explants have a limited lifespan (only a few hours after tissue collection) and, therefore, cannot be used for long term studies, they preserve all properties of the original epithelium, especially its morphological differentiation and intensive ciliary activity. Thus, an oviductal explant-binding assay may be closer to the situation in vivo than cultured monolayers. Baillie et al. (1997) demonstrated that the numbers of human spermatozoa that bound to polarized explants were significantly greater than the numbers that bound to dissociated and passaged epithelial cultured monolayers. This finding indicates that cell polarity is an important factor for such associations in vitro and represents an advantage of using an explant system to characterize the first steps in the sperm-oviduct interaction represented by initial sperm binding to oviductal epithelial cells.

In the present study, a modified oviduct explant assay based on the methodology developed by Suarez et al. (1991) was used to quantify the number of spermatozoa bound to a defined surface area and to determine some factors influencing sperm-oviduct binding. One of the major requirements for assay accuracy is the presence of a strong relationship between sperm concentration and binding capacity. Therefore, the dependence of spermoviduct binding on the number of spermatozoa added to explants was investigated. Furthermore, the sensitivity of the binding with respect to individual boars and the relationship of individual binding index to conventional sperm characteristics of ejaculates were examined to investigate whether sperm-oviduct binding is selective. This system was then used to determine whether anatomical origin of explants, reproductive status and stage of oestrous cycle of the female donor are factors that affect the ability of epithelial cells to bind boar spermatozoa. Finally, the capacity of epididymal and ejaculated boar spermatozoa to attach to the oviductal epithelium was compared to investigate the possible role of the seminal plasma proteins that coat sperm surfaces in sperm-oviduct binding.

\section{Materials and Methods}

\section{Chemicals}

Unless otherwise stated, chemicals were obtained from Merck (Darmstadt, Germany), Roth (Karlsruhe, Germany) and Sigma Chemical Company (Steinheim, Germany). All were of suitably high purity.

\section{Media}

A modified Tyrode's balanced salt solution (TALP; Parrish et al., 1988) containing $6 \mathrm{mg} \mathrm{BSA} \mathrm{ml}^{-1}$ and $2.2 \mathrm{mg}$ sodium pyruvate $\mathrm{ml}^{-1}$ was used for coincubation of spermatozoa with the explants; it was equilibrated before use at $39^{\circ} \mathrm{C}$ for $1 \mathrm{~h}$ in a humidified atmosphere containing $5 \% \quad \mathrm{CO}_{2} \quad\left(\mathrm{pH} 7.4,300 \mathrm{mOsm} \mathrm{kg}^{-1}\right)$. Androhep without EDTA (mod. Androhep) was used for dilution of spermatozoa (Waberski et al., 1994); it consisted of $144 \mathrm{mmol}$ glucose $\mathrm{I}^{-1}, 27.2 \mathrm{mmol}$ tri-sodium citrate-2-hydrate $\mathrm{I}^{-1}$, $14.3 \mathrm{mmol} \mathrm{NaHCO}_{3} \mathrm{I}^{-1}$ and 37.0 mmol Hepes I-1 $\mathrm{pH}^{-1}$, $290 \mathrm{mOsm} \mathrm{kg}^{-1}$ ). After preparation, all media were passed through a $0.2 \mu \mathrm{m}$ single use filter unit (Minisart Sartorius, Göttingen).

\section{Sperm preparation for the basic experiments}

Ejaculates were collected from healthy fertile boars of the Institute's colony and used within 30 min. Sperm concentration of native ejaculates was evaluated by sperm counting using chambers and sperm motility was assessed microscopically on pre-warmed slides. The assessment of the morphologically abnormal forms in the collected ejaculates was performed after fixation in formol citrate (Hancock, 1956) according to the classification described by Krause (1966). Motile spermatozoa were selected by the swim-up procedure: $1 \mathrm{ml}$ ejaculated semen was layered under $10 \mathrm{ml}$ mod. Androhep in $20 \mathrm{ml}$ centrifuge tubes. After incubation for $1 \mathrm{~h}$ at $39^{\circ} \mathrm{C}$ in a waterbath, a $2 \mathrm{ml}$ aliquot was removed from the top of each tube. Spermatozoa were concentrated by centrifugation at $150 \mathrm{~g}$ for $10 \mathrm{~min}$. The sperm pellet was resuspended with 1-2 ml mod. Androhep and adjusted to the desired sperm concentration (from $1.25 \times 10^{6}$ to $2.00 \times 10^{7}$ cells $\mathrm{ml}^{-1}$ for Expt 1 and $5 \times 10^{6}$ cells $\mathrm{ml}^{-1}$ for Expts 2 and 3 ). Epididymal spermatozoa were obtained from the caudal region of epididymides collected immediately after castration; the epididymal tubules were cut with a scalpel, and the exuded semen was collected in $1.5 \mathrm{ml}$ plastic Eppendorf tubes, immediately diluted in mod. Androhep and adjusted to $5 \times 10^{6}$ spermatozoa $\mathrm{ml}^{-1}$ (Expt 3).

\section{Preparation of the oviductal explants}

Fallopian tubes were obtained at the local abattoir from gilts and sows at different stages of the oestrous cycle (assessed by examination of ovarian function) and transported immediately to the laboratory in ice-cold PBS $\left(150 \mathrm{mmol} \mathrm{NaCl} \mathrm{I-1,} 11.7 \mathrm{mmol} \mathrm{NaH}_{2} \mathrm{PO}_{4} \mathrm{I}^{-1}\right.$ and $2.5 \mathrm{mmol} \mathrm{KH}_{2} \mathrm{PO}_{4} \mathrm{I}^{-1}$; $\mathrm{pH} 7.4,280 \mathrm{mOsm} \mathrm{kg}^{-1}$ ). Explants were prepared using a modified procedure based on the methodology described by Suarez et al. (1991). After rinsing in PBS, the surrounding tissues were removed carefully; the tubes were cut longitudinally, straightened as much as possible and placed within a paraffin wax-filled glass well. Under a stereomicroscope, pairs of $0.5-1.0 \mathrm{~mm}$ pieces from longitudinal folds (referred to henceforth as explants) were cut off from different parts (isthmus and ampulla) of the oviductal epithelium using 'mini vannas iris spring' scissors (Fine Science Tools GmbH, Heidelberg). The explants were placed in TALP medium and stored in a refrigerator at $4^{\circ} \mathrm{C}$ until used $(<2 \mathrm{~h})$. 
The viability of the oviductal explants was assessed in each experiment by evaluating their ciliary activity. Only explants with rapidly beating cilia and an intact ciliary explant ridge (longitudinal fold with ciliated cells on the top) were used.

\section{Addition of spermatozoa to explants}

Pairs of explants from a given region of the oviduct were equilibrated in a $60 \mu \mathrm{l}$ droplet of TALP medium at $39^{\circ} \mathrm{C}$ in a humidified atmosphere containing $5 \% \mathrm{CO}_{2}$ until cilia showed vigorous activity. The sperm suspension in mod. Androhep was incubated under the same conditions for at least $5 \mathrm{~min}$ before $20 \mu \mathrm{l}$ sperm suspension was added to the droplet (final droplet volume $80 \mu \mathrm{l}$ ). After coincubation for $15 \mathrm{~min}$, the two explants were freed of loosely attached spermatozoa by washing through two TALP droplets (each $60 \mu \mathrm{l}$ ) and vigorous stirring; the explants were then transferred to warm slides and covered with coverslips supported by silicon grease, before videomicroscopical analysis of sperm binding.

The sperm-bearing oviductal explants (mounted on slides as described above) were placed on a warm stage under an inverted microscope (Inversmikroskop Zeiss IM 35, Jena) and videotaped using a black and white video camera (Kappa, CF 8/1), a video monitor (WV-BM 1400, Panasonic) and a video cassette recorder (SLV-E 720, VHS, Sony). The explants were first videotaped using bright field optics at $\times 63$ magnification. Three fields per explant were then videotaped using bright field optics at $\times 320$ magnification. The specimen was focused continuously throughout the videotaping process to ensure optimal detection of spermatozoa through explants. Videotaping of each slide (pair of explants from the same female donor) was completed in about $12 \mathrm{~min}$. Subsequently, on replay of the videos, the number of bound spermatozoa was counted at the edges and surface of the three fields per explant. For accurate sperm counting a transparency film was fixed on the video screen and spermatozoa at different focus levels were marked with a black felt-tip pen. As the geometrical shape of the videotaped fields with bound spermatozoa differed among different regions, the surface of the fields varied (by two to three times). The surface area was included in the quantification of binding to take into account the surface variation and heterogeneity of sperm binding. The surface area of each observed particular explant region was calculated from the videotape using image analysis software (Mika Medical $\mathrm{GmbH}$, Version 2.0, Germany), a monitor (Trinitron, Sony) and a Computer system (Dell 450/M). The number of spermatozoa bound to the oviductal explant per $0.01 \mathrm{~mm}^{2}$ was then calculated: this was defined as the binding index.

\section{Definition of binding index}

The methodology for determining the binding index was established from data derived from 57 binding experiments (material from 57 females and six males). For each of the three videotaped observations from each explant, the numbers of spermatozoa bound were obtained and related to the surface area of the observed region (using analysis of variance (General Linear Model procedure)), and the numbers of spermatozoa bound were shown to be dependent on the surface area. The numbers of spermatozoa bound per $0.01 \mathrm{~mm}^{2}$ surface of each of three videotaped regions subjected to square transformation (in order to obtain normally distributed data) was reproducible between the two explants tested from each animal.

The binding index was calculated for each explant within a pair as the sum of the sperm numbers bound to each videotaped region divided by the sum of the areas of these three regions (binding index $=\left(N_{1}+N_{2}+N_{3}\right) /\left(S_{1}+S_{2}\right.$ $+S_{3}$ ). The overall binding index of the pair of explants (referred to henceforth as the average binding index $(B I)$ of each single experiment) was defined as an arithmetic mean of two binding indices calculated for these two explants from the given sow/gilt: $B I=\left(B I_{1}+B I_{2}\right) / 2$.

\section{Experimental design}

In the first set of experiments (Expt 1), the relationship between number of spermatozoa added and sperm binding index was examined by coincubation of explants collected from the first $\mathrm{cm}$ of the oviductal isthmus with increasing sperm numbers (from $2.5 \times 10^{4}$ to $4.0 \times 10^{5}$ sperm cells per $80 \mu \mathrm{l}$ droplet). Five tests were made, including five sows and five boars; in each test, a pair of explants for a given sow was tested with spermatozoa from a given boar. In the second set of experiments (Expt 2), the effects of region (isthmus and ampulla), stage of the oestrous cycle of the female, and the individual boar were examined. Material from 42 sows, 28 gilts and six boars was used. Sperm concentrations were $10^{5}$ sperm cells per $80 \mu \mathrm{l}$ droplet. Expts 1 and 2 were performed with ejaculated spermatozoa. The third experimental set (Expt 3) was designed to study the binding capacity of epididymal spermatozoa versus ejaculated spermatozoa. Ejaculated spermatozoa and epididymal spermatozoa (obtained via castration) were obtained from three boars and coincubated with pairs of isthmic explants ( $10^{5}$ sperm cells per $80 \mu$ l droplet).

\section{Scanning electron microscopy (SEM)}

Explants were recovered from the isthmic region of the oviduct and coincubated with spermatozoa as described above (15 min coincubation, two rinses with TALP). After subsequent washing with physiological $\mathrm{NaCl}$, the explants were immersed in $5 \%(\mathrm{w} / \mathrm{v})$ glutaraldehyde for $24 \mathrm{~h}$, and then post-fixed in $1 \%(\mathrm{w} / \mathrm{v})$ osmium tetroxide buffers in $0.1 \mathrm{~mol}$ sodium cacodylate $\mathrm{I}^{-1}$ for $1 \mathrm{~h}$. The samples were critical-point dried and sputtered with gold. Examination was performed with a Zeiss scanning electron microscope DSM 940.

\section{Statistical analysis}

The data analysis with respect to binding index and conventional sperm parameters was performed using the statistical program package SAS (SAS Institute Inc, Cary, $\mathrm{NC}$ ). Linear regression analysis (procedure REG) was used 


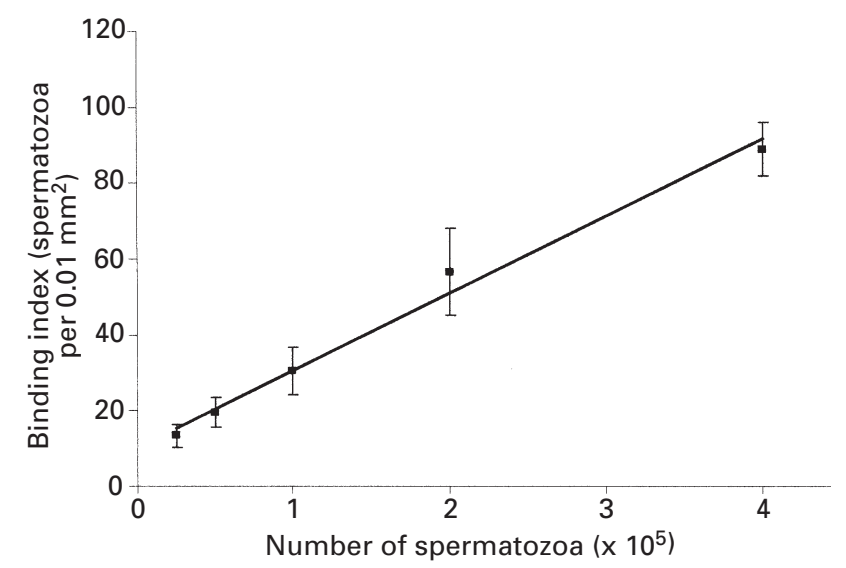

Fig. 1. Linear dependence of number of spermatozoa on number of spermatozoa bound to the epithelium. Final sperm concentration increased from $2.5 \times 10^{4}$ to $4.0 \times 10^{5}$ spermatozoa per $80 \mu \mathrm{l}$ droplet. The following linear regression model is valid: binding index $=10.4+20.3 n$ where $n=$ number of spermatozoa. Data are mean $\pm \operatorname{SEM}(n=5)$.

to determine the dependence of the binding index on the number of spermatozoa added. The normality of the distributions was tested by the procedure UNIVARIATE; for ANOVA, the general linear model procedure (GLM) was used. Differences were considered significant when $P \leqslant 0.05$. Correlation analysis by Pearson (procedure CORR) was used to determine the relationships between binding index and sperm parameters.

\section{Results}

\section{Morphology of sperm attachment}

Spermatozoa became attached over the whole surface of the explant. Binding was variable: dense in some areas, sparse in others and even absent in some areas. Almost all of the spermatozoa remained motile and appeared to adhere to the explants by the rostral surface of the head. Scanning electron microscopy revealed that the sperm heads bound preferentially to the cilia or in deeper regions of ciliated epithelial cells between the cilia (data not shown).

\section{Investigation of linearity of binding index with number of spermatozoa}

The results of Expt 1 indicated that there was a strong linear relationship between the number of spermatozoa added (increasing sperm concentrations under standardized conditions from $2.5 \times 10^{4}$ to $4.0 \times 10^{5}$ cells per $80 \mu \mathrm{l}$ droplet) and the number of spermatozoa bound to the epithelium (expressed as binding index) (Fig. $1 ; P \leqslant 0.001$, $\left.r^{2}=0.8, n=5\right)$.

\section{Comparison of isthmus and ampulla}

No significant differences in sperm binding were observed when isthmic explants were compared with ampullary

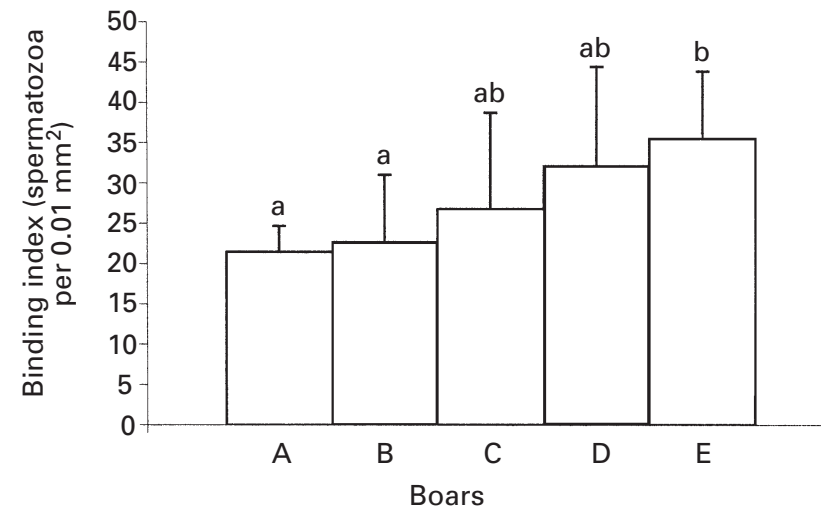

Fig. 2. Binding index of spermatozoa per $0.01 \mathrm{~mm}^{2}$ explant surface in five individual boars. Values are mean \pm SD. abc Values with different letters are significantly different $(P \leqslant 0.05)$.

explants (material from ten sows tested with spermatozoa from six boars). The binding index of isthmic explants was $34.2 \pm 9.4$ spermatozoa per $0.01 \mathrm{~mm}^{2}$ and the corresponding binding index of ampullary explants was $35.3 \pm 8.2$ spermatozoa per $0.01 \mathrm{~mm}^{2}($ mean $\pm \mathrm{SD} ; n=10)$.

\section{Effect of stage of oestrous cycle}

No significant difference was found with respect to stage of oestrous cycle of female donors when material from 57 luteal phase donors was compared with material from 13 oestrus phase donors. The binding index for luteal phase material was $29.8 \pm 11.0$ spermatozoa per $0.01 \mathrm{~mm}^{2}$ and the binding index for oestrous phase material was $28.9 \pm 10.5$ spermatozoa per $0.01 \mathrm{~mm}^{2}$ (mean $\pm \mathrm{SD}$ ).

\section{Effect of reproductive status}

When explants obtained from 28 gilts were compared with material from 42 sows, no significant difference in sperm binding could be detected. The binding index for explants recovered from sows was $29.3 \pm 12.6$ spermatozoa per $0.01 \mathrm{~mm}^{2}$ and the binding index for explants recovered from gilts was $30.3 \pm 8.3$ spermatozoa per $0.01 \mathrm{~mm}^{2}$ (mean $\left.\pm \mathrm{SD}\right)$.

\section{Effect of individual boars and relationship between binding index and sperm parameters}

When results from 56 binding experiments involving sperm samples from five different boars were subjected to ANOVA, a significant effect of boar was detected $(P \leqslant 0.05)$. The binding indices of individual boars are shown (Fig. 2). Descriptive data for conventional semen parameters of the five boars are also shown (Table 1).

The binding index showed a significant negative correlation with both the percentage of morphologically abnormal spermatozoa $(r=-0.41 ; P \leqslant 0.001)$ and the percentage of spermatozoa with cytoplasmic droplets $(r=-0.29 ; P \leqslant 0.05)$ (Table 2$)$. There was also a significant 
Table 1. Sperm parameters for five individual boars

\begin{tabular}{|c|c|c|c|c|c|}
\hline Boar & $\begin{array}{c}\text { Native } \\
\text { motility (\%) }\end{array}$ & $\begin{array}{l}\text { Motility after } \\
\text { swim-up (\%) }\end{array}$ & $\begin{array}{c}\text { Motility after } \\
\text { resuspension } \\
(\%)\end{array}$ & $\begin{array}{l}\text { Cytoplasmic } \\
\text { droplets } \\
(\%)\end{array}$ & $\begin{array}{c}\text { Morphologically } \\
\text { abnormal } \\
\text { spermatozoa } \\
(\%)\end{array}$ \\
\hline $\mathrm{A}(n=5)$ & $88.4 \pm 4.2$ & $62.4 \pm 10.9$ & $75.0 \pm 5.0$ & $69.7 \pm 12.1$ & $90.6 \pm 3.5$ \\
\hline $\mathrm{B}(n=12)$ & $91.2 \pm 5.7$ & $80.4 \pm 11.6$ & $82.1 \pm 8.1$ & $25.5 \pm 13.8$ & $34.0 \pm 17.5$ \\
\hline$C(n=12)$ & $88.8 \pm 6.8$ & $75.0 \pm 17.0$ & $76.3 \pm 17.6$ & $26.1 \pm 6.0$ & $46.5 \pm 7.6$ \\
\hline $\mathrm{D}(n=13)$ & $83.1 \pm 12.7$ & $80.0 \pm 5.4$ & $80.0 \pm 7.6$ & $30.7 \pm 27.5$ & $43.3 \pm 35.4$ \\
\hline $\mathrm{E}(n=14)$ & $92.7 \pm 2.9$ & $86.1 \pm 4.0$ & $90.4 \pm 3.1$ & $9.3 \pm 14.2$ & $14.9 \pm 13.4$ \\
\hline
\end{tabular}

Values are mean $\pm \mathrm{SD}$.

Table 2. Correlation between different variables tested for individual boars

\begin{tabular}{|c|c|c|c|c|c|c|}
\hline & $\begin{array}{l}\text { Binding } \\
\text { index }\end{array}$ & $\begin{array}{c}\text { Native } \\
\text { motility (\%) }\end{array}$ & $\begin{array}{l}\text { Motility after } \\
\text { swim-up (\%) }\end{array}$ & $\begin{array}{c}\text { Motility after } \\
\text { resuspension } \\
(\%)\end{array}$ & $\begin{array}{l}\text { Cytoplasmic } \\
\text { droplets } \\
(\%)\end{array}$ & $\begin{array}{c}\text { Morphologically } \\
\text { abnormal } \\
\text { spermatozoa } \\
(\%)\end{array}$ \\
\hline Native motility $(\%)$ & 0.21 & 1 & - & - & - & - \\
\hline Motility after swim-up (\%) & 0.02 & 0.24 & 1 & - & - & - \\
\hline Motility after resuspension (\%) & 0.02 & $0.27^{*}$ & $0.89 * *$ & 1 & - & - \\
\hline Cytoplasmic droplets $(\%)$ & $-0.41^{* *}$ & $-0.47^{* *}$ & $-0.39 * *$ & $-0.42^{* *}$ & 1 & - \\
\hline Morphologically abnormal spermatozoa (\%) & $-0.29 *$ & $-0.43^{* *}$ & $-0.31^{*}$ & $-0.28^{*}$ & $0.89^{* *}$ & 1 \\
\hline
\end{tabular}

Binding index: number of spermatozoa per $0.01 \mathrm{~mm}^{2}$.

* and ${ }^{* *}$ indicate correlations that are significant $(P \leqslant 0.05$ and $P \leqslant 0.001$, respectively).

negative correlation between the motility of the sperm sample and the percentages of morphologically abnormal spermatozoa and spermatozoa with cytoplasmic droplets. There was no correlation between binding index and sperm motility.

\section{Comparison between ejaculated and epididymal spermatozoa}

Normally ejaculated spermatozoa were compared with epididymal spermatozoa to test the influence of maturation on the binding index and the influence of accessory sex gland fluid. After being used regularly as sperm donors in earlier experiments ( $n=31$ observations with normally ejaculated spermatozoa), three boars were castrated and spermatozoa from their cauda epididymides were tested ( $n=15$ observations with collected epididymal spermatozoa). The data from the first set of 31 experiments with ejaculated spermatozoa were then compared with the data from the 15 experiments with epididymal spermatozoa. The epididymal spermatozoa had significantly lower binding indices than did the ejaculated spermatozoa $(P \leqslant 0.05)$. The mean binding index of epididymal spermatozoa was $15.1 \pm 6.1$ spermatozoa per $0.01 \mathrm{~mm}^{2}$, whereas the mean binding index of normally ejaculated spermatozoa was $28.4 \pm 11.4$ spermatozoa per $0.01 \mathrm{~mm}^{2}$. Values for individual boars are shown (Table 3). The binding indices of epididymal spermatozoa before and after the swim-up procedure were compared to investigate whether these differences might be due to different treatments of ejaculated and epididymal spermatozoa: no significant difference was observed (data not shown).

\section{Discussion}

The results of the present study reveal differences in the initial binding capacity of boar spermatozoa to oviductal epithelium in relation to sperm morphology and contact of spermatozoa with seminal fluid, indicating a selective function of sperm-oviduct binding. A modified oviductal explant assay (Suarez et al., 1991) was used for this in vitro approach. The number of spermatozoa bound to the epithelial explant, adjusted numerically to the surface area of the analysed region and averaged in an appropriate manner, revealed the sperm binding capacity to be a quantitative, sensitive and reproducible parameter. The validity of this model for quantitative binding studies is ensured by the strong linear relationship between binding index and the number of spermatozoa added. Therefore, the pig explant assay, as used in the present study, is revealed as a biologically and mathematically well-founded in vitro system.

Given the functions of the oviductal reservoir, such as transport and selection of spermatozoa in the female reproductive tract, maintenance of sperm fertility and regulation of capacitation, it is surprising that no significant influence of the localization of explant recovery, cycle stage 
Table 3. Comparison of binding affinity of ejaculated and epididymal spermatozoa to oviductal explants

\begin{tabular}{lcc}
\hline Boars & Ejaculated spermatozoa & Epididymal spermatozoa \\
\hline A & $21.5 \pm 3.2(n=5)$ & $11.8 \pm 6.0(n=6)$ \\
C & $26.8 \pm 11.9(n=12)$ & $16.0 \pm 5.1(n=3)$ \\
D & $32.3 \pm 11.9(n=14)$ & $18.0 \pm 5.9(n=6)$ \\
\hline
\end{tabular}

Values are mean \pm SD.

Binding index: number of spermatozoa per $0.01 \mathrm{~mm}^{2}$.

Ejaculated spermatozoa had a significantly higher binding affinity than did epididymal spermatozoa in the three boars tested $(P \leqslant 0.05)$.

or reproductive state of the female donor was found. In vivo, the sperm reservoir is located in the caudal isthmus of the oviduct (Hunter and Nicol, 1983; Hunter, 1984; Hunter and Wilmut, 1984). The equal binding ability of spermatozoa to the explants recovered from the isthmic and ampullar tissues indicates that the binding sites are located through the oviduct. Similar results were reported for cattle by Lefebvre et al. (1995a), who proposed that sperm binding might be limited to the isthmic part of the oviduct in vivo as spermatozoa encounter the isthmus first. However, in vitro binding studies in horses showed some regional and cyclic effects (Thomas et al., 1994). As reported by Baillie et al. (1997), the significant differences between binding to explants of the different regions of the oviduct (preferential binding to isthmic explants compared with ampullar explants) were also observed in humans. Conflicting results about regional and hormonal influences on pig spermoviduct binding in vitro have been reported (Raychoudhury and Suarez, 1991; Suarez et al., 1991). However, recent in vivo studies with spermatozoa deposited surgically into either the caudal isthmus or the rostral ampulla of oviducts in gilts showed a 1-2 $\mathrm{h}$ advantage in fertilization of the isthmic sperm population (Hunter et al., 1998). Although boar spermatozoa bind in both the isthmus and ampulla, lectin binding sites determining carbohydrate recognition differ between regions and cycle stages (Raychoudhury et al., 1993, Walter and Bavdek, 1997). This finding might become decisive during regulation of the capacitation process in vivo. It must be emphasized that the observations made in the present study were made during a relatively short incubation time in the isolated explant system without addition of hormones. Female hormones modulate binding to oviductal reservoir (Raychoudhury and Suarez, 1991; Suarez et al., 1991), capacitation rate and sperm activation at the time of ovulation (Hunter, 1997; Hunter et al., 1998). In addition, in vitro systems miss functional specialization of different regions of the oviduct due to the lack of local endocrine modulation by adjacent ovaries (Hunter et al., 1998) which may, therefore, limit the use of such systems for studying time-associated changes in sperm maturation and activation. The present study focussed on initial binding capacity of boar spermatozoa in a standardized in vitro system and showed clear differences among individual boars with respect to the binding index. The individuality of binding has been reported for stallion spermatozoa (Thomas and Ball, 1996), indicating that these differences may be related to the different fertility of individual donors. The ejaculates used in the present study were collected from fertile boars; however, no data allowing the comparative ranking of fertility were available to examine the relationship between binding index and fertility.

Although sperm motility is a well-accepted criterion for ejaculate quality, the absence of correlation between motility and oviduct binding index is not surprising. In vivo, motility is important for overcoming the barriers in the female reproductive tract (Hunter, 1995; Suarez, 1996). However, sperm motility apparently has no crucial importance for the quantitative success of sperm-oviduct binding in vitro, possibly due to the free accessibility of explants. The results of the present study indicate that the mere binding of spermatozoa to oviductal epithelium is not related to motility activation, and other signalling systems might be involved.

The binding index correlated negatively with the percentage of morphological alterations and percentage of spermatozoa with cytoplasmic droplets. Similar results were reported by Thomas and Ball (1996), who demonstrated that spermatozoa of stallion ejaculates with a low percentage of pathological alterations bound to a higher extent to cultured epithelial cells than did spermatozoa of ejaculates with a high percentage of such alterations. Cytoplasmic droplets are taken as a characteristic of immature spermatozoa (Kaplan et al., 1984) and enhanced prevalence of boar spermatozoa with cytoplasmic droplets is associated negatively with fertility (Waberski et al., 1994). The results of the present study may indicate that a certain stage of maturation or morphological integrity is needed to complete the binding. Although binding of spermatozoa with cytoplasmic droplets to explants was observed, the lower binding index of boars with ejaculates with a high percentage of such morphological alteration provides evidence for the selective function of sperm binding to the oviductal epithelium. It is widely believed that selection of viable spermatozoa occurs during passage of spermatozoa through the lower parts of the female tract and through the uterotubal junction (Hunter, 1988; Mburu et al., 1996). From the results of the present study and the observation that spermatozoa bound to oviductal epithelium in vitro have intact acrosomes (Suarez et al., 1991; Thomas and Ball, 1996; Gualtieri and Talevi, 2000), it seems that the initial binding of spermatozoa to the oviduct itself, in addition to overcoming mechanical barriers at the uterotubal junction, presents a mechanism for selection of competent spermatozoa. The nature of the underlying selective mechanism is not clear and may lie in differences in the expression of binding sites on the spermatozoa.

Sperm-oviduct binding index also differed between ejaculated spermatozoa and spermatozoa from the cauda epididymides from the same boar. In contrast to ejaculated spermatozoa, epididymal spermatozoa have not made contact with fluids from accessory sex glands. The lower 
binding index for epididymal compared with ejaculated spermatozoa may indicate a role of seminal plasma components for sperm-oviduct interaction. There is evidence from a number of studies that no major amounts of seminal plasma may pass through the narrow lumen of the uterotubal junction of pigs in oestrus (Mann et al., 1956; Hunter et al., 1972); however, seminal plasma infused into the oviductal isthmus delays fertilization considerably (Hunter and Hall, 1974). In addition, preincubation of spermatozoa with seminal plasma hinders fertilization of oocytes in vitro (Nagai et al., 1984). However, at the time of ejaculation, a coat of seminal plasma proteins becomes associated with the sperm surface (Töpfer-Petersen, 1999) and, thus, such proteins are likely to enter the oviductal sperm reservoir where they could contribute to spermoviduct binding. The major part of these proteins is eventually removed during capacitation. Fazeli et al. (1999) demonstrated preferential binding of uncapacitated spermatozoa to oviductal epithelial cells in pigs. It is likely that capacitation-induced removal of decapacitation factors of seminal plasma from the sperm surface may be responsible for the low binding ability of capacitated cells.

In conclusion, initial sperm-oviduct binding in pigs seems to be selective for morphologically normal spermatozoa and there is evidence for a potential role of seminal plasma components in binding. The oviductal explant-binding assay represents a useful approach for studying sperm-oviduct interactions and, at the same time, is a potential tool to evaluate the quality of boar ejaculates with relevance for fertility.

The authors are very grateful R. A. P. Harrison for assistance in writing the results into correct English and for constructive discussion. The study was supported by DFG (Grants Wa 106/2-1, Tö 114/3-3 and 114/3-4), Minitüb (Landshut, Germany) and Minitube America (Verona, WI).

\section{References}

Baillie HS, Pacey AA, Warren MA, Scudamore IW and Barratt CL (1997) Greater numbers of human spermatozoa associate with endosalpingeal cells derived from the isthmus compared with those from the ampulla Human Reproduction 12 1985-1992

DeMott RP, Lefebvre R and Suarez SS (1995) Carbohydrates mediate the adherence of hamster sperm to oviductal epithelium Biology of Reproduction 52 1395-1403

Dobrinski I, Ignotz GG, Thomas PGA and Ball BA (1996a) Role of carbohydrates in the attachment of equine spermatozoa to uterine tubal (oviductal) epithelial cells in vitro. American Journal of Veterinary Research 57 1635-1639

Dobrinski I, Suarez SS and Ball BA (1996b) Intracellular calcium concentration in equine spermatozoa attached to oviductal epithelial cells in vitro. Biology of Reproduction $\mathbf{5 4}$ 783-788

Fazeli A, Duncan AE, Watson PF and Holt WV (1999) Sperm-oviduct interaction: induction of capacitation and preferential binding of uncapacitated spermatozoa to oviductal epithelial cells in porcine species Biology of Reproduction 60 879-886

Gualtieri R and Talevi R (2000) In vitro-cultured bovine oviductal cells bind acrosome-intact sperm and retain this ability upon sperm release Biology of Reproduction 62 1754-62

Hancock JL (1956) The morphology of boar spermatozoa Journal of the Royal Microscopical Society 76 84-97
Hunter RHF (1981) Sperm transport and reservoirs in the pig oviduct in relation to the time of ovulation Journal of Reproduction and Fertility 63 109-117

Hunter RHF (1984) Pre-ovulatory arrest and periovulatory redistribution of competent spermatozoa in the isthmus of the pig oviduct Journal of Reproduction and Fertility 72 203-211

Hunter RHF (1988) The Fallopian Tubes: Their Role in Fertility and Infertility pp 53-80. Springer Verlag, Berlin, Heidelberg

Hunter RHF (1995) Ovarian endocrine control of sperm progression in the Fallopian tubes. In Oxford Reviews of Reproductive Biology pp 85-124 Ed. HM Charlton. Oxford University Press, Oxford

Hunter RHF (1997) Sperm dynamics in the female genital tract: interactions with Fallopian tube microenvironments. In Microscopy of Reproduction and Development: A Dynamic Approach pp 35-45 Ed. PM Motta. Antonio Delfino, Rome

Hunter RHF and Hall JP (1974) Capacitation of boar spermatozoa: synergism between uterine and tubal environment Journal of Experimental Zoology $\mathbf{1 8 8} 203-214$

Hunter RHF and Nicol R (1983) Transport of spermatozoa in the sheep oviduct: preovulatory sequestering of cells in the caudal isthmus Journal of Experimental Zoology 228 121-128

Hunter RHF and Wilmut I (1984) Sperm transport in the cow: periovulatory redistribution of viable cells within the oviduct Reproduction, Nutrition and Development 24 597-608

Hunter RHF, Karagiannidis A and Mann T (1972) Fate of seminal plasma after intrauterine insemination in the pig Journal of Reproduction and Fertility 29 303-305

Hunter RHF, Flechon B and Flechon JE (1991) Distribution, morphology and epithelial interactions of bovine spermatozoa in the oviduct before and after ovulation: a scanning electron microscope study Tissue and Cell 23 641-656

Hunter RHF, Huang WT and Holtz W (1998) Regional influences of the Fallopian tubes on the rate of boar sperm capacitation in surgically inseminated gilts Journal of Reproduction and Fertility 114 17-23

Kaplan M, Russell LD, Peterson RN and Martan J (1984) Boar sperm cytoplasmic droplets: their ultrastructure, their numbers in the epididymis and at ejaculation and their removal during isolation of sperm plasma membranes Tissue and Cell 16 455-468

Krause D (1966) Untersuchungen am Bullensperma unter Berücksichtigung der fertilitätsdiagnostischen Bedeutung der Befunde HabilitationsSchrift. Tierärztliche Hochschule, Hannover

Lefebvre R and Suarez SS (1996) Effect of capacitation on bull sperm binding to homologous oviductal epithelium Biology of Reproduction 54 575-582

Lefebvre R, Chenoweth PJ, Drost M, LeClear CT, MacCubbin M, Dutton JT and Suarez SS (1995a) Characterization of the oviductal sperm reservoir in cattle Biology of Reproduction 53 1066-1074

Lefebvre R, DeMott RP, Suarez SS and Samper JC (1995b) Specific inhibition of equine sperm binding to oviductal epithelium. In Equine Reproduction VI pp 689-696 Eds DC Sharp and FW Bazer. Society for the Study of Reproduction, Madison

Lefebvre R, Lo MC and Suarez SS (1997) Bovine sperm binding to oviductal epithelium involves fucose recognition Biology of Reproduction $\mathbf{5 6}$ 1198-1204

Mann T, Polge C and Rowson LEA (1956) Participation of seminal plasma during the passage of spermatozoa in the female reproductive tract of the pig and horse Journal of Endocrinology 13 133-140

Mburu JN, Einarsson S, Lundeheim N and Rodriguez-Martinez H (1996) Distribution, number and membrane integrity of spermatozoa in the pig oviduct in relation to spontaneous ovulation Animal Reproduction Science 45 109-121

Nagai T, Niwa K and Iritani A (1984) Effect of sperm concentration during preincubation in a defined medium on fertilization in vitro of pig follicular oocytes Journal of Reproduction and Fertility 70 271-275

Overstreet JW and Cooper GW (1978a) Sperm transport in the reproductive tract of the female rabbit: I. The rapid transit phase of transport Biology of Reproduction 19 101-114

Overstreet JW and Cooper GW (1978b) Sperm transport in the reproductive tract of the female rabbit: II. The sustained phase of transport Biology of Reproduction 19 115-132 
Parrish JJ, Susko-Parrish J, Winer MA and First NL (1988) Capacitation of bovine sperm by heparin Biology of Reproduction 38 1171-1180

Raychoudhury SS and Suarez SS (1991) Porcine sperm binding to oviductal explants in culture Theriogenology 36 1059-1070

Raychoudhury SS, Suarez SS and Buhi WC (1993) Distribution of lectin binding sites in the oviducts of cycling and hormone-treated pigs Journal of Experimental Zoology 265 659-668

Smith TT (1998) The modulation of sperm function by the oviductal epithelium Biology of Reproduction 58 1102-1104

Smith TT and Yanagimachi R (1991) Attachment and release of spermatozoa from the caudal isthmus of the hamster oviduct Journal of Reproduction and Fertility 91 567-573

Suarez SS (1987) Sperm transport and motility in the mouse oviduct: observations in situ. Biology of Reproduction 36 203-210

Suarez SS (1996) Hyperactivated motility in sperm Journal of Andrology 17 $331-335$

Suarez SS (1998) The oviductal sperm reservoir in mammals: mechanisms of formation Biology of Reproduction 58 1105-1107

Suarez SS (1999) Regulation of sperm transport in the mammalian oviduct. In The Male Gamete: From Basic Science to Clinical Applications pp 71-80 Ed. C Gagnon. Cache River Press, Vienna, IL

Suarez SS (2001) Carbohydrate-mediated formation of the oviductal sperm reservoir in mammals Cells Tissues Organs 168 105-112

Suarez S, Redfern K, Raynor P, Martin F and Phillips DM (1991) Attachment of boar sperm to mucosal explants of oviduct in vitro: possible role in formation of a sperm reservoir Biology of Reproduction 44 998-1004

Suarez SS, Brockman K and Lefebvre R (1997) Distribution of mucus and sperm in bovine oviducts after artificial insemination Biology of Reproduction $\mathbf{5 6}$ 447-453

Thomas P and Ball B (1996) Cytofluorescent assay to quantify adhesion of equine spermatozoa to oviduct epithelial cells in vitro. Molecular Reproduction and Development 43 55-61

Thomas P, Ball B and Brinsko S (1994) Interaction of equine spermatozoa with oviduct epithelial cell explants is affected by estrous cycle and anatomic origin of explants Biology of Reproduction $51222-228$

Töpfer-Petersen $\mathbf{E}$ (1999) Carbohydrate-based interactions on the route of a spermatozoon to fertilization Human Reproduction 5 314-329

Waberski D, Meding S, Dirksen G, Weitze KF, Leiding C and Hahn R (1994) Fertility of long-termed stored boar semen: influence of extender (Androhep and Kiev), storage time and plasma droplets in the semen Animal Reproduction Science 36 145-151

Walter I and Bavdek S (1997) Lectin binding patterns of porcine mucosa and endometrium during the estrous cycle Journal of Anatomy 190 299-307

Received 16 October 2000

First decision 4 December 2000

Accepted 26 January 2001. 